\title{
POLINIZAÇÃO DE MORANGUEIRO POR Apis mellifera EM AMBIENTE PROTEGIDO ${ }^{1}$
}

\author{
EUNICE OLIVEIRA CALVETE ${ }^{2}$, HÉLIO CARLOS ROCHA ${ }^{3}$, FERNANDO TESSARO 4 , \\ DILETA CECCHETTI ${ }^{5}$, ALEXANDRE AUGUSTO NIENOW ${ }^{6}$, JOANA TERESA LOSS $^{7}$
}

RESUMO- Este trabalho objetivou comparar a produtividade e a qualidade dos frutos comerciáveis no morangueiro, em ambiente protegido, utilizando a espécie de abelha Apis mellifera em relação à ausência de um agente polinizador. Foram instalados dois experimentos, utilizando-se das cultivares Camarosa, Oso Grande, Diamante e Aromas (tratamentos), no período de 05 de maio a 19 de dezembro de 2006. No primeiro experimento, não havia polinizadores (testemunha). O segundo foi polinizado pela espécie de abelha Apis mellifera. Os tratamentos (cultivares) foram dispostos, em cada experimento, em um delineamento completamente casualizado, com seis repetições. Foram avaliadas características de rendimento, bem como análise físico-química dos frutos de cada cultivar. Quanto ao rendimento, a maior produção obtida foi com a cultivar Camarosa tanto na ausência quanto na presença de polinizadores (907,46 g. planta-1 e 1.054,93 g. planta-1 respectivamente), ao passo que a cultivar Oso Grande apresentou menor número de frutos deformados.

Termos para indexação: Fragaria x ananassa Duch., agente polinizador, abelhas, produtividade.

\section{STRAWBERRY POLINIZATION THROUGH Apis mellifera IN PROTECTED ENVIRONMENT}

\begin{abstract}
This work objectified to compare the productivity and the quality of the strawberry marketable fruits in protected environment, using the species of bee Apis mellifera in relation of the absence of a pollination agent. It was installed two experiments using the cultivates Camarosa, Oso Grande, Diamante and Aromas (treatments), in the period of May 5th until December $19^{\text {th }}$ of 2006 . The first experiment did not have pollination agents (control). The second was pollinated by the species of bee Apis mellifera. The treatments (cultivars) had been arranged, in each experiment in a randomized block with 6 repetitions. It was evaluated yield characteristics, as well as analysis physico-chemical of the fruits of each cultivar. For the yield, the biggest production was in cultivar Camarosa, for the first and the second experiment $(907,46 \mathrm{~g}$. plant $^{-1}$ and 1054,93 g. plant ${ }^{-1}$, respectively), in the way that the cultivate Oso Grande, presented minor number of damage fruits.
\end{abstract}

Index terms: Fragaria x ananassa Duch., pollinator agent, bees, productivity.

\section{INTRODUÇÃO}

A produção mundial de morangueiro vem sendo incrementada desde níveis próximos a 800.000 t (anos 70) até próximos a 4.000 .000 t em 2007 (FAOSTAT, 2008). No Brasil, a produção está ao redor 2.800 t (FAOSTAT, 2008), distribuída nas regiões Sul, Sudeste e Centro-Oeste. O Estado do Rio Grande do Sul contribui com $25 \%$ do total produzido. O seu cultivo teve grande impulso comercial no início da década de 70, concentrando-se no Vale do Rio Caí e na Serra Gaúcha para a produção de morangos de mesa. Já na região de Pelotas, tem como principal destino a indústria. O morango é uma das frutas de maior importância econômica nessas regiões. O interesse pelo cultivo é devido à elevada rentabilidade da cultura, ao amplo conhecimento e aceitação da fruta pelo consumidor e pela diversidade de opções de comercialização e processamento do morango (Sanhueza et al., 2008).

Nas últimas décadas, observa-se que o Brasil vem aumentando a superfície cultivada e a produtividade de morangueiro, em consequência da incorporação de novas tecnologias, como a utilização

\footnotetext{
${ }_{1}^{1}$ (Trabalho 037-09). Recebido em 30-01-2009. Aceito para publicação em: 19-10-2009. Projeto financiado pela Fundação de Amparo à Pesquisa do Rio Grande do Sul- Brasil (Processo n. ${ }^{\circ}$ 04/0540.3 - PROCOREDES)

${ }^{2}$ Eng $^{\mathrm{a}}$. Agr ${ }^{\mathrm{a}}$., Dra., profa. de Olericultura da Faculdade de Agronomia e Medicina Veterinária (FAMV) da Universidade de Passo Fundo (UPF), Campus I, Passo Fundo-RS, Cx. Postal 611, CEP 99001-970, calveteu@upf.br

${ }^{3}$ Eng. Agr., Dr., prof. de Apicultura da FAMV/UPF, Campus I, Passo Fundo-RS, Cx. Postal 611, CEP 99001-970, helio@upf.br ${ }^{4}$ Acadêmico de Agronomia da FAMV/UPF e Bolsista CNPq. ftessaro@pop.com.br

${ }^{5}$ Matemática, Ms., profa. de Estatística da UPF. cecchetti@upf.br

${ }^{6}$ Eng. Agr., Dr., prof. de Fruticultura da FAMV/UPF, Campus I, Passo Fundo-RS, Cx. Postal 611, CEP 99001 970, alexandre@upf.br

${ }^{7}$ Acadêmica de Agronomia da FAMV/UPF e Bolsista FAPERGS. 74515@upf.br
} 
de novas cultivares, cultivo em ambiente protegido, fertirrigação, produção em substrato, entre outras. Entretanto, o cultivo em ambientes protegidos, principalmente estufas agrícolas, pode apresentar alta porcentagem de frutos deformados em decorrência de uma polinização deficiente.

Em estudo realizado por Antunes et al. (2007), com as cvs. Oso Grande, Tudla e Chandler, observaram que a presença da abelha-jataí na polinização em ambiente protegido tem significativa importância na porcentagem de frutos comerciáveis e no aumento da produtividade. A recomendação é a utilização de quatro colmeias de Tetragonisca angustula para cada $170 \mathrm{~m}^{2}$ de área protegida para essas cultivares. Entretanto, nesse mesmo trabalho, a cv. Dover mostrou-se menos dependente de agentes polinizadores.

Segundo Brazanti (1989), a maioria das cultivares comerciais de morangueiro possui flores hermafroditas, pois não há coincidência da liberação do pólen com a receptividade do estigma, necessitando da fecundação cruzada. Portanto, para produzir frutos de qualidade, necessitam de uma perfeita polinização das flores, possível na presença de agentes polinizadores, principalmente insetos e o vento. Por outro lado, na deformação do fruto, intervêm numerosos fatores, embora todos eles estritamente relacionados entre si, tais como, baixas temperaturas, ausência de luminosidade, excesso de umidade relativa do ar, polinização deficiente, falta de viabilidade do pólen e características da cultivar, entre outras (Verdier citado por Medina, 2003).

A introdução de abelhas nas áreas com culturas que necessitam de polinização cruzada, é uma técnica que permite aumentar a produtividade e a qualidade dos frutos. Na presença de insetos polinizadores, os ganhos na produção podem ocorrer em todos ou em alguns componentes, como número e massa de frutos, formato e tamanho em função das características de cada cultivar. O tamanho dos frutos é um dos aspectos mais considerados, uma vez que o formato e o tamanho valorizam mais os frutos no mercado in natura (Malagodi - Braga \& Kleinert, 2002).

As abelhas Apis mellifera são manejadas em diversos países para a produção de morangueiro (Free, 1993). Contudo, essas abelhas apresentam eficiência na polinização do morangueiro se conduzidas próximas ao cultivo, pois o pólen das flores do morangueiro não é atrativo em relação a outras culturas (Crane \& Walker, 1984). Geralmente, a polinização do morangueiro recebe pouca atenção a esse manejo, pois na maioria das vezes o cultivo é realizado em condições naturais, onde os agentes polinizadores se fazem presentes (Malagodi - Braga \& Kleinert, 2002). Entretanto, o cultivo em condições protegidas merece atenção a esse assunto.

Desta forma, este trabalho objetivou comparar a produtividade e a qualidade dos frutos comerciáveis do morangueiro produzidos em ambiente protegido, na presença e ausência de Apis mellifera.

\section{MATERIAL E MÉTODOS}

O trabalho foi conduzido em estufa agrícola de $510 \mathrm{~m}^{2}$, instalada no sentido nordeste-sudeste, com estrutura em aço galvanizado, teto semicircular, coberta com filme de polietileno de baixa densidade (PEBD), com aditivo antiUV e espessura de 150 micra. Para o estudo essa estrutura foi dividida em compartimentos de $170 \mathrm{~m}^{2}$. As laterais da estufa foram revestidas de malha de sombreamento de cor branca ("clarite”), assim como as repartições. Apenas as cortinas laterais de PEBD foram manejadas para proporcionar ventilação.

Foram instalados dois experimentos em cinco de maio de 2006, utilizando-se das cultivares Camarosa, Oso Grande, Diamante e Aromas (tratamentos). No primeiro experimento, não havia polinizadores (testemunha). O segundo foi polinizado por Apis mellifera, utilizando-se de uma colmeia para 170 $\mathrm{m}^{2}$ de estufa. Os tratamentos (cultivares), em cada experimento, foram dispostos em delineamento completamente casualizados, com seis repetições. Cada parcela constituiu-se de 20 plantas espaçadas de 0,30 $\mathrm{X} 0,30 \mathrm{~m}$, sendo destas, seis avaliadas $(\mathrm{N}=6)$.

As parcelas (canteiros) foram revestidas com plástico de PEBD preto com espessura de 30 micra, 30 dias após o transplante. A irrigação foi realizada por um sistema de gotejamento localizado, composto por mangueiras fixas e por gotejadores de acordo com os espaçamentos entre plantas $(30 \mathrm{~cm})$. Uma vez por semana, foi realizada a fertirrigação na formulação descrita por Calvete et al. (2007).

Os núcleos compostos de cinco caixilhos para $170 \mathrm{~m}^{2}$ de estufa foram introduzidos em 14 de agosto de 2006 e retirados em 12 de setembro, 09 de outubro e 10 de novembro, por ocasião da realização dos seguintes tratamentos fitossanitários: Folpet, Tebuconazole, Difenoconazole e Tiofatanato Metílico para o controle de Micosferela (Mycosphaerella fragariae (Tul.) Lindau); Enxofre e Benomil para o controle de oídio (Sphaerotheca macularis); Chlorfenatyr e Abamectin para o controle de ácaro-rajado (Tetranychus urticae); e Dimethoate para o controle de pulgões (Capitophorus fragaefolii; Cerosipha forbesi), misturados com espalhante adesivo Silwet L-77 e/ou Tuwin. Os núcleos foram recolocados 
oito dias após a aplicação, em virtude do período de carência dos produtos.

As características de rendimento avaliadas nas plantas de morangueiro constituíram do número e da massa fresca (g) total de frutos por planta, produção de frutos deformados e comerciáveis (g). Em relação à qualidade dos frutos, foram efetuadas análises físico-químicas nos frutos de sólidos solúveis ( ${ }^{\circ} \mathrm{Brix}$ ) através do refratômetro CarlZeiss de 0-30\%; pH (Peagâmetro TEC-3MP) e análise de coloração externa dos frutos pelo sistema tridimensional $\mathrm{L} \mathrm{a}^{*} \mathrm{~b}^{*}$. Para esse parâmetro, foi utilizado um espectrofotômetro de Refletância Difusa (Hunter Lab), modelo ColorQuest II, com sensor óptico geométrico de esfera. No sistema Hunter de cor, corrigido pela CIE, os valores $\mathrm{L}^{*}$ (luminosidade) flutuam entre zero (preto) e 100 (branco), -a* (verde) até $+\mathrm{a}^{*}$ (vermelho), e -b* (azul) até $+b^{*}$ (amarelo). Calculou-se a relação $a^{*} / b^{*}$.

Com a A. mellifera, foram analisadas as seguintes variáveis: a) área de cria (mediu-se a superfície em $\mathrm{cm}^{2}$ do favo nos caixilhos do núcleo antes e após a colocação dentro da estufa). Esta superfície continha ovos, larvas, pupas e alimento (mel); b) número de visitas de abelhas por flor. Esta variável foi analisada das 8 às 17 horas, nos dias 26; 27 e 28 de outubro de 2008.

Durante o período de avaliação de campo, foi monitorada diariamente a temperatura relativa do ar através de um termoigrógrafo da marca Sato, modelo NS-II-Q, instalados na parte interna da estufa.

Os resultados das avaliações nas plantas em cada experimento foram submetidos à análise de variância, e as médias, comparadas pelo teste de Tukey, ao nível de 5\% de significância. Para efeito de comparação dos experimentos, foi efetuada a análise conjunta de dados.

Os resultados da variável área de cria das colmeias de $A$. mellifera e o número médio de visitas nas flores das cultivares de morangueiro foram comparados pelo teste t, a 5\% de significância, sendo os dados transformados por log +10 .

\section{RESULTADOS E DISCUSSÃO}

Na ausência do agente polinizador (Tabela1), observamos que as cultivares mostram-se semelhantes quanto à produção total e comercial de frutos. Entretanto, a cv. Camarosa apresenta menor produção de frutos deformados que as cvs. Aromas e Diamante, sem diferenciar de Oso Grande, mostrando que a presença de frutos deformados depende, além de outros fatores, da cultivar. Um aspecto importante a ser considerado é a quantidade de pólen e a sua forma de liberação. Medina (2003), comparando a liberação de pólen pelas anteras nas cvs. Camarosa e Ventana, verificou que há diferença entre ambas, apresentando média de 4.913,5 e 8.482,0 grãos de pólen, respectivamente. Adicionalmente, concluiu que a máxima liberação de pólen na cv. Ventana é produzido durante o segundo e terceiro dias após a antese, enquanto Camarosa necessita de seis dias para liberar uma quantidade similar, o que a torna dependente do pólen de outra flor.

Na presença de A. mellifera, as cultivares apresentaram diferenças, em todas as variáveis estudas (Tabela 1), confirmando observações efetuadas por outros autores em relação à necessidade de polinizadores para maximizar a produção de morangueiro (Malagodi-Braga \& Kleinert, 2002; Calvete et al., 2007). A cv. Camarosa apresentou maior produção total (1.054,9 g) e comercial por planta (1.004,3 g), destacando-se das demais. Entretanto, a cv. Oso Grande, mesmo com menor produção total e comercial (748,2 g e 711,0 g, respectivamente), obteve menor massa de frutos deformados (76,3 g). Estes resultados estão de acordo com Connor \& Martin (1973), que relatam as variações apresentadas pelas cultivares em relação à polinização. Essas variações, geralmente, dizem respeito à morfologia e à fisiologia floral, determinando o grau de dependência aos agentes polinizadores (Medina, 2003).

Analisando conjuntamente os dois experimentos em relação à produção total (Tabela 2), observa-se que apenas a cv. Camarosa obteve resposta positiva com a introdução de abelhas $A$. mellifera, embora Free (1993) e Moore (1969) tenham demonstrado que a produção de frutos de morangueiro tem alta correlação com a polinização quanto ao peso, formato e tamanho.

Com relação às características químicas dos frutos de morangueiro nas diferentes cultivares, verificou-se que, quando não foi utilizado agente polinizador, a cv. Camarosa apresentou o maior valor de ${ }^{\circ} \mathrm{Brix}$, diferindo apenas da cv. Oso Grande, que obteve o menor valor (Tabela 3). Entretanto, na presença de $A$. mellifera, foi a cv. Oso Grande que obteve maior teor de açúcar (6,9 ${ }^{\circ}$ Brix), estatisticamente superior às demais cultivares. $\mathrm{O}$ valor obtido na cv. Camarosa corrobora o obtido por Dias et al. (2002), de 6,0-6,5 ( ${ }^{\circ}$ Brix), mas é inferior ao encontrado por Calvete et al. (2008) (9,3 ${ }^{\circ}$ Brix).

Com relação à coloração externa dos frutos (Tabela 3), o comportamento das cultivares foi semelhante quando foram cultivadas sem agente polinizador. Entretanto, quando se utilizou $A$. mellifera, a cultivar Aromas apresentou coloração vermelha mais intensa, diferindo, entretanto, apenas da cv. Camarosa. A relação a*/b* foi semelhante entre as 
cultivares. Segundo Antonelli et al. (1988), na presença de polinizadores, os ganhos na produção e na qualidade podem ocorrer em todos ou em alguns dos componentes. É importante ressaltar que a tonalidade vermelha do morango está ligada ao pigmento de antocianina (Aaby et al., 2005), e sua concentração é influenciada por vários fatores, como níveis de irrigação e adubação, clima, grau de maturação e características genéticas de cada cultivar (Anttonen et al., 2006). A característica da cor, entretanto, é muito importante para o consumo de morango in natura e está relacionada às características físicas, ao valor nutricional e ao efeito benéfico à saúde. No sul do Uruguai, os pesquisadores Carballo et al. (2006) também obtiveram maior intensidade da cor vermelha na cv. Aromas, entre sete cultivares avaliadas, sem considerar a polinização, sendo a relação entre as cores vermelha e amarela de 7,26, valor muito superior ao obtido para esta cultivar no presente trabalho $(1,3)$.

Com relação às avaliações direcionadas para A. mellifera, verificou-se que, na área de cria (Tabela 4), houve diminuição na quantidade de ovos, após a retirada final dos núcleos da estufa. Provavelmente, este fato deve-se às variações de temperatura ocorridas no ambiente interno da estufa $\left(5-38^{\circ} \mathrm{C}\right)$, durante o período experimental. Provavelmente, a manutenção da temperatura da cria, ao redor de 32 ${ }^{\circ} \mathrm{C}$, não foi mantida em função do número reduzido de abelhas adultas para essa tarefa. Isso porque, nas primeiras horas da manhã, as temperaturas de uma estufa agrícola são muito baixas, ocorrendo médias de temperaturas mínimas entre $1,0^{\circ} \mathrm{C}$ a $3,0^{\circ} \mathrm{C}$ superiores às do ambiente externo (Buriol et al., 1993). Entretanto, durante o dia, a temperatura do ar é sempre maior do que a céu aberto, devido à diminuição das perdas de energia por radiação infravermelha (Calvete \& Tessaro, 2008). A diminuição no número de ovos pode ter ocorrido em função das altas temperaturas, que provocaram a desidratação e a morte do embrião, ou pela paralisação da postura pela rainha, ou ambos os casos. Os ovos que sobreviveram ao efeito ambiental, eclodiram, proporcionando maior número de larvas após a retirada do núcleo da estufa. Já com relação às pupas, o decréscimo, provavelmente, foi decorrente de mortes, em virtude da emergência e das altas temperaturas $\left(38^{\circ} \mathrm{C}\right)$. Quanto ao alimento (mel), não houve diferença significativa $(P>0,05)$. Neste sentido, verifica-se que o manejo da A. mellifera em ambiente protegido foi prejudicial às abelhas, em função das variações térmicas ocorridas no período do experimento. Resultados semelhantes foram obtidos utilizando a Jataí como polinizadora de cultivares de morangueiro (Antunes et al., 2007). Desta forma, sugerem-se novas abordagens de pesquisa que atendam as abelhas e o serviço de polinização.

Com respeito às visitas de $A$. mellifera realizadas nas flores das quatro cultivares, e também a temperatura do ambiente (Figura 1a) ao longo do dia, observa-se que o maior número ocorreu ao redor das 12 horas, onde cada abelha visitou, em média, 1,6 flor por planta em Camarosa e Aromas; em Diamante e Oso Grande, este número foi, respectivamente, 1,3 e 1,1. O número de visitas é inferior ao obtido pelo pesquisador Medina (2003), cerca de 2,13 flores por planta no morangueiro em ambiente protegido. Um dos aspectos que deve ser levado em consideração no presente trabalho, é a temperatura do ambiente elevada $\left(33^{\circ} \mathrm{C}\right)$ nas horas de maior visitação. De acordo com Medina (2003), em trabalho realizado em Huelva, Espanha, a temperatura ótima para A. mellifera e Bombus terrestris situa-se entre 20 e $25^{\circ} \mathrm{C}$. Cabe ressaltar que o manejo das abelhas em estufas agrícolas é um procedimento delicado, devido à grande variação de temperatura que ocorre nesse ambiente ao longo do dia. Na Figura 1b, verifica-se que todas as cultivares receberam igual número de visitas pelas abelhas e, entretanto, observou-se variação entre elas em relação à deformação de frutos total por planta. As cultivares Camarosa $(11,6 \%)$ e Oso Grande (10,16 \%) obtiveram menor porcentagem do que Diamante $(19,51 \%)$ e Aromas (17,04\%). Esses dados nos mostram que, além dos fatores temperatura e umidade relativa do ar, importantes para a visitação dos polinizadores às flores, outros, como os citados por Medina (2003), estão relacionados com frutos malformados, como a deficiência ou a má absorção do nutriente boro. 


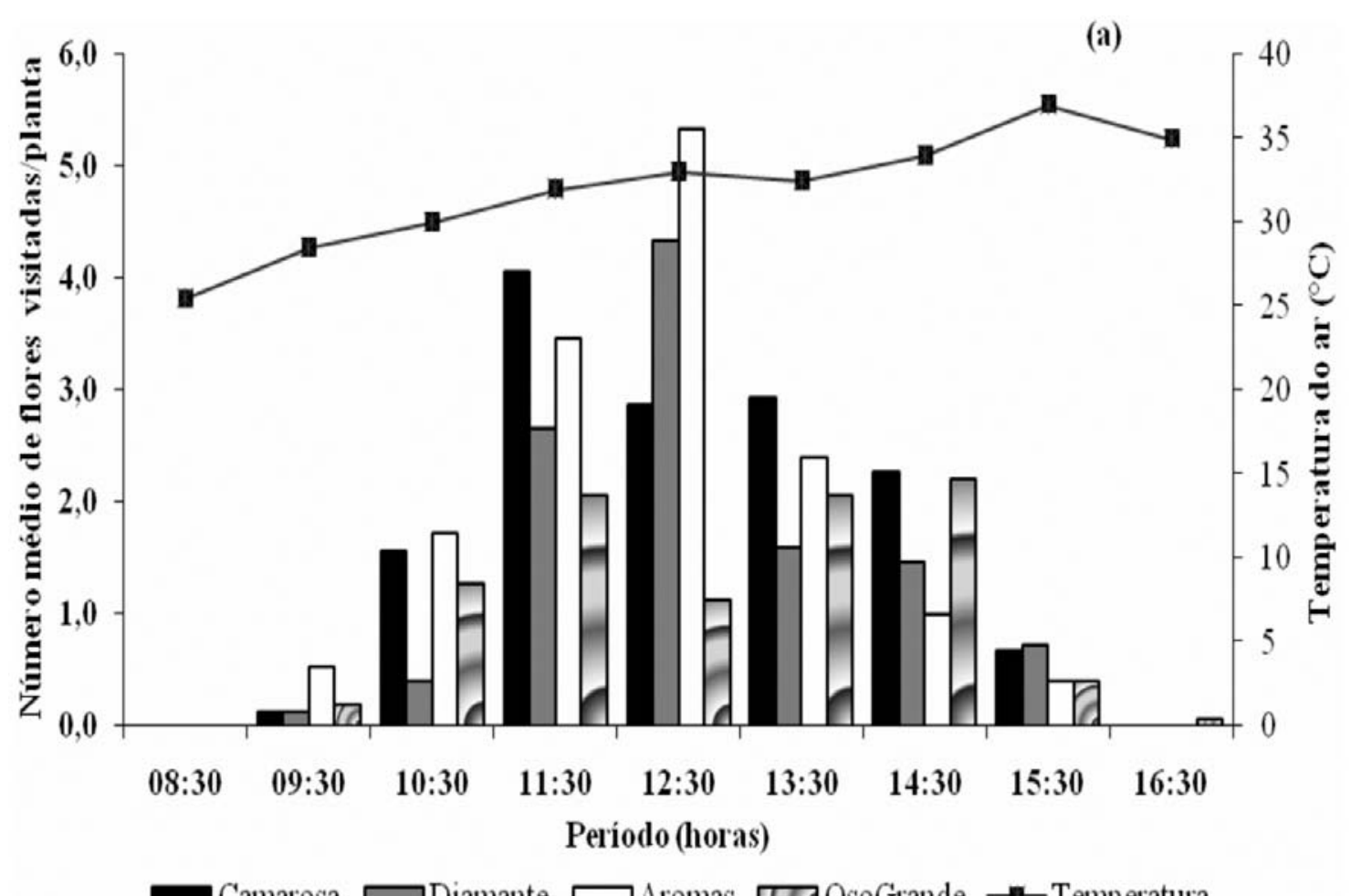

Camarosa $\square$ Diamante $\square$ Aromas $\square$ OsoGrande $\rightarrow$-Temperatura

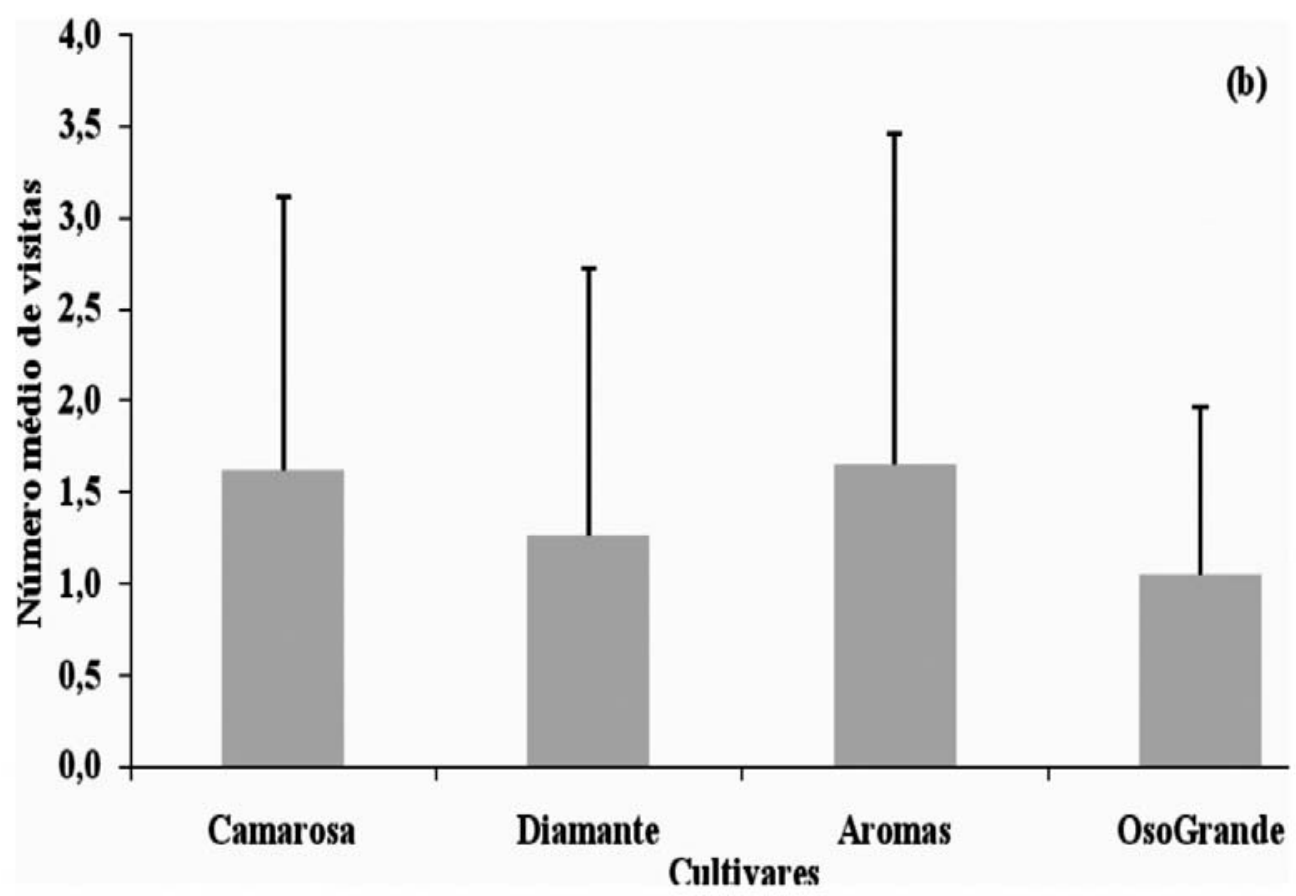

FIGURA 1 - Número médio de flores visitadas por Apis mellifera no período das 8h30 às 16 h30 e temperatura do ar (a) ; número médio de visitas ( \pm d.p.) em quatro cultivares de morangueiro, no período das 8h30 às 16 h30 (b). Passo Fundo, UPF/FAMV. 2006. 
TABELA 1 - Produção (g) média de frutos total, comercializáveis e deformados por planta, em quatro cultivares de morangueiro, na presença e ausência de Apis mellifera. Passo Fundo, UPF/ FAMV. 2006.

\begin{tabular}{|c|c|c|c|}
\hline \multicolumn{4}{|c|}{ Ausência de Apis mellifera } \\
\hline \multicolumn{4}{|c|}{ Média de frutos (g) planta ${ }^{-1}$} \\
\hline & Total & Comerciálizáveis (g) & Deformados \\
\hline Camarosa & $907,5^{\mathrm{ns}}$ & $847,2^{\mathrm{ns}}$ & 160,8 a \\
\hline Oso Grande & 904,1 & 962,8 & $180,1 \mathrm{ab}$ \\
\hline Diamante & 899,2 & 845,9 & $236,9 \mathrm{~b}$ \\
\hline Aromas & 880,6 & 824,6 & $240,5 \mathrm{~b}$ \\
\hline CV (\%) & 11,2 & 11,6 & 19,3 \\
\hline \multicolumn{4}{|c|}{ Presença de Apis mellifera } \\
\hline Camarosa & 1054,9 a & 1004,3 a & $123,0 \mathrm{~b}$ \\
\hline Oso Grande & 748,2 с & 711,0 c & 76,3 a \\
\hline Diamante & $948,7 \mathrm{ab}$ & $900,0 \mathrm{ab}$ & 185,7 c \\
\hline Aromas & 839,1 bc & 788,6 bc & $143,9 \mathrm{~b}$ \\
\hline CV (\%) & 10,6 & 10,7 & 17,7 \\
\hline
\end{tabular}

Médias seguidas pela mesma letra na coluna não diferem significativamente entre si, pelo teste de Tukey, ao nível de 5\% de significância. ns= não significativo

TABELA 2- Produção (g) média total de frutos por planta em quatro cultivares de morangueiro, na presença e na ausência de Apis mellifera. Passo Fundo, UPF/FAMV. 2006.

\begin{tabular}{|c|c|c|c|c|c|}
\hline Tratamento & Camarosa & Oso Grande & Diamante & Aromas & CV (\%) \\
\hline Ausência de $A$. mellifera & $847,2 \mathrm{aB} *$ & 962,8 aA & 845,9 aA & 824,6 aA & 11,65 \\
\hline Presença de A. mellifera & 1004,3 aA & $711,1 \mathrm{cA}$ & 900,03 abA & 788,7 bcA & 10,72 \\
\hline $\mathrm{CV}(\%)$ & 11,16 & 17,11 & 18,87 & 15,69 & \\
\hline
\end{tabular}

TABELA 3 - Características físico-químicas em quatro cultivares de morangueiro, em ambiente protegido. Passo Fundo, UPF/FAMV. 2006.

\begin{tabular}{|c|c|c|c|c|c|}
\hline \multicolumn{6}{|c|}{ Ausência de Apis mellifera } \\
\hline & \multirow{2}{*}{$\begin{array}{c}\text { Sólidos solúveis } \\
\left({ }^{\circ} \text { Brix }\right)\end{array}$} & \multicolumn{2}{|c|}{ Coloração externa } & \multirow{2}{*}{ Relação a*/b* } & \multirow{2}{*}{$\mathrm{pH}$} \\
\hline & & $\mathrm{a}^{*}$ & $\mathrm{~b}^{*}$ & & \\
\hline Camarosa & $6,1 \mathrm{a}$ & $28,8^{\mathrm{ns}}$ & $21,6^{\mathrm{ns}}$ & $1,3^{\mathrm{ns}}$ & $3,5 b$ \\
\hline Oso Grande & $4,7 \mathrm{~b}$ & 30,0 & 21,9 & 1,3 & $3,9 \mathrm{a}$ \\
\hline Diamante & $5,2 \mathrm{ab}$ & 30,7 & 19,3 & 1,6 & $3,5 b$ \\
\hline Aromas & $5,3 \mathrm{ab}$ & 31,2 & 17,9 & 1,7 & $3,6 \mathrm{~b}$ \\
\hline $\mathrm{CV}(\%)$ & 13,1 & 10,5 & 21,4 & - & 2,9 \\
\hline \multicolumn{6}{|c|}{ Presença de Apis mellifera } \\
\hline Camarosa & $5,3 \mathrm{~b}$ & $33,7 \mathrm{~b}$ & $24,4^{\mathrm{ns}}$ & $1,3^{\mathrm{ns}}$ & $5,9 \mathrm{a}$ \\
\hline Oso Grande & $6,9 \mathrm{a}$ & $35,0 \mathrm{ab}$ & 29,8 & 1,1 & $4,7 \mathrm{~b}$ \\
\hline Diamante & $5,6 \mathrm{~b}$ & $37,5 \mathrm{ab}$ & 26,9 & 1,4 & $4,4 \mathrm{~b}$ \\
\hline Aromas & $5,5 \mathrm{~b}$ & $39,0 \mathrm{a}$ & 28,7 & 1,3 & $4,5 b$ \\
\hline $\mathrm{CV}(\%)$ & 10,0 & 8,1 & 18,5 & - & 1,8 \\
\hline
\end{tabular}

Médias seguidas pela mesma letra na linha não diferem significativamente entre si, pelo teste de Tukey, ao nível de 5\% de significância. ns= não significativo 
TABELA 4 - Número médio ( \pm d.p.) de ovos, larvas, pupas e mel de. A. melífera por $\mathrm{cm}^{2}$ de favos, antes e após a introdução dos núcleos, nas estufas com morangueiro. Passo Fundo, UPF/FAMV. 2006.

\begin{tabular}{lccc}
\hline \multirow{2}{*}{ Variáveis } & \multicolumn{2}{c}{ Média \pm D.P. cm $^{-2}$} & \multirow{2}{*}{$P$} \\
\cline { 2 - 3 } Ovo & \multicolumn{1}{c}{ Antes } & Depois & $0,0003^{*}$ \\
Larva & $2,66 \pm 0,36$ & $1,36 \pm 0,69$ & $0,0353^{*}$ \\
Pupa & $2,66 \pm 0,68$ & $3,29 \pm 0,11$ & $0,0026^{*}$ \\
Alimento & $3,30 \pm 0,13$ & $1,69 \pm 0,99$ & $0,4105^{\text {ns }}$ \\
\hline
\end{tabular}

*Siginificativo ao nível de 5\% . ns= não significativo.

\section{CONCLUSÕES}

Com base nos resultados obtidos conclui-se, que:

1-Para a cultivar Camarosa, é indicado utilizar A. mellifera como agente polinizador, resultando mais frutos comercializáveis, melhoria da polinização e redução do número e da porcentagem de frutos deformados.

2-Para o cultivo de morangueiro em ambientes protegidos visando à maior produção de frutos total, sem a utilização de insetos polinizadores, recomendam-se as cultivares Oso Grande, Diamante e Aromas.

\section{AGRADECIMENTOS}

Os autores agradecem à FAPERGS, pelos recursos recebidos, e ao $\mathrm{CNPq}$, pela concessão de bolsa PIBIC ao acadêmico de Agronomia Fernando Tessaro.

\section{REFERÊNCIAS}

AABY, K.; SKREDE, G.; WROLSTAD, R. E. Phenolic composition and antioxidant activities in flesh and achenes of strawberries (Fragaria X ananassa). Journal of Agricultural and Food Chemistry, Los Angeles, v.53, n.10, p.4032-4040, 2005.

ANTONELLI, D. F.; MA YER, D. F.; BURGETT, D. M.; SJULIN, T. Pollinating insects and the strawberry yields in the Pacific Northwest. American Bee Journal, Hamilton, v.128, n.9, p.618-620,1988.
ANTTONEN, M. J.; HOPPULA, K. I.; NESTBY, R.; VERHEUL, M. J.; KARJALAINEN, R. O. Influence of fertilization, mulch color, early forcing, fruit order, planting date, shading, growing environment, and genotype on the contents of selected phenolics in strawberry (Fragaria x ananassa Duch.) fruits. Journal of Agricultural and Food Chemistry, Los Angeles, v.54, n.7, p.2614-2620, 2006.

ANTUNES, O. T.; CALVETE, E. O.; ROCHA, H. C.; NIENOW, A. A.; CECCHETTI, D.; RIVA, E.; MARAN, R. Produção de cultivares de morangueiro polinizadas pela abelha-jataí em ambiente protegido. Horticultura Brasileira, Brasília, v.1, n.25, p. 9499, 2007.

BRAZANTI E. E. La fresa. Madri: Mundi-Prensa, 1989. 386p.

BURIOL, G. A.; SCHNEIDER, F. M.; ESTEFANEL, V.; ANDRIOLO, G. L.; MEDEIROS, S. L. P. Modificação na temperatura mínima do ar causada por estufas de polietileno transparente de baixa densidade. Revista Brasileira de Agrometeorologia, Santa Maria, v. 1, n. 1, p. 43-49, 1993.

CALVETE, E. O.; MARIANI, F.; WESP, C. de L.; NIENOW, A. A.; CASTILHOS, T.; CECCHETTI, D. Fenologia, produção e teor de antocianina de cultivares de morangueiro em ambiente protegido. Revista Brasileira de Fruticultura, Jaboticabal, v.30, n.2, p. 396-401, 2008.

CALVETE, E. O. ; NIENOW, A. A.; WESP, C. de L.; CESTONARO, L.; MARIANI, F.; FIOREZE, I.; CASTILHOS, T.; CECCHETTI, D. Produção hidropônica de morangueiro em sistemas de colunas verticais, sob cultivo protegido. Revista Brasileira de Fruticultura, Jaboticabal, v.29, n.3, p. 524-529, 2007. 
CALVETE, E. O.; TESSARO, F. Ambiente protegido: aspectos gerais. In: PETRY,C. Plantas ornamentais: aspectos para a produção. 2.ed. Passo Fundo: Editora Universidade de Passo Fundo, 2008. p. 24-45.

CARBALLO, S.; SCALONE, M.; BORTHAGUAY, M. 2006. Calidad de Consumo en frutilla (Fragaria X ananassa Duch.). Disponível em: <http://www. inia.org.uy/online/site/6834I1.php>. Acesso em: 05 set. 2006.

CONNOR, L. J.; MARTIN, E. C. Components of pollination of commercial strawberry in Michigan. HortScience, Alexandria, v.8, n.4, p.304-306. 1973.

CRANE, E.; WALKER, P. Pollination directory for world crops. London: International Bee Research Association, 1984. 183p.

DIAS, M. S. C.; RIBEIRO JÚNIOR, P. M.; SILVA, M. S.; SANTOS, L. 0.; CANUTO, R. S.; CASTRO, M. V.; COSTA, S. M. Caracterização físicoquímica de morangos cultivados na região norte de Minas Gerais. IN: CONGRESSO BRASILEIRO DE FRUTICULTURA, 17., 2002. Belém. Anais... Belém: Sociedade Brasileira de Fruticultura, 2002. CD-ROM.
FAOSTAT. Disponível em: <htp://www.faostat.fao. org/site/567/desktopDefault.aspx?pageID>. Acesso em: 12 dez. 2008.

FREE, J. B. Insect pollination of crops. $2^{\text {nd }}$ ed. Londres: Academic Press, 1993. 684p.

MALAGODI-BRAGA, K. S.; KLEINERT, A. M. P. A produção de morangos sob efeito da polinização por jataí (Tetragonisca angustula). In: ENCONTRO SOBRE ABELHAS, 5., 2002. Anais... Ribeirão Preto: Confederação Brasileira de Apicultura, 2002. CD-ROM.

MEDINA, J. L. Análisis y evolución agronômica de lãs deformaciones de fruto em fresa. Posibles soluciones. In: JORNADAS AGRÍCOLAS Y COMERCIALES DE EL MONTE, 20., Huelva, 2003. Anais... Huelva: Caja Rural, 2003. p.101-115.

MOORE, J. N. Insect pollination of strawberries. Journal of the American Society for Horticultural Science, Alexandria, v. 94, p.362-364, 1969.

SANHUEZA, R. M. V.; HOFFMANN, A.; ANTUNES, L. E.; FREIRE, J. de M. Sistema de produção de morango para mesa na região da serra gaúcha e encosta superior do Nordeste. Disponível em: $<$ http://sistemasdeproducao.cnptia.embrapa.br/ FontesHTML/Morango/ MesaSerraGaucha/ index. htm>. Acesso em: 30 out. 2008. 